\title{
The prognostic significance of age in operated and non-operated colorectal cancer
}

\author{
Jing $\mathrm{Li}^{1,2}$, Zhu Wang ${ }^{1}$, Xin Yuan ${ }^{1}$, Lichun $\mathrm{Xu}^{2^{*}}$ and Jiandong Tong ${ }^{1 *}$
}

\begin{abstract}
Background: The prognostic significance of age in colorectal cancer remains controversial. Our purpose was to determine the impact of age at diagnosis on cause- specific survival and overall survival in patients with colorectal cancer.

Methods: Using Surveillance, Epidemiology, and End Results (SEER) population-based data, we identified 226,430 patients with colorectal cancer diagnosed between 1996 and 2005. Patients were separated into 10-year age groups. Five-year cancer cause-specific survival and overall survival data were obtained. Kaplan-Meier methods were adopted and multivariable Cox regression models were built for the analysis of long-term survival outcomes and risk factors.
\end{abstract}

Results: In the operated group, those aged 51-60 had the best prognosis with 5-year cause-specific survival of 72.3\% and 5-year overall survival of 68.3\%.In the non-operated group, those of young age 15-30 had the best prognosis with 5-year cause-specific survival of $21.2 \%$ and 5-year overall survival of 18.2\%, and there was continued worsening in causespecific survival and overall survival with increasing age, except for a small increase in the 51-60 age group ( $P<0.001)$. Multivariable analysis demonstrated a statistically significant disadvantage in cause-specific survival in patients older than $60(P<0.001)$, but the difference between the $51-60$ age group and the younger age group $(15-30,31-40,41-50)$ wasn't statistically significant $(P>0.05)$ in both operated and non-operated patients.

Conclusions: There was no apparent difference in survival in colorectal cancer patients 60 and younger, but in those older than 60 years, there was worsening in overall survival and cause-specific survival in both operated and nonoperated patients.

Keywords: Colorectal cancer, Age, Survival analysis

\section{Background}

Colorectal cancer $(\mathrm{CRC})$ is one of the most common malignancies and is ranked as the second leading cause of cancer-related deaths in the USA [1]. Median age at diagnosis is 69 years, and patients younger than 50 years represent approximately $10 \%$ of CRC [1-3]. The incidence of CRC has been increasing in younger patients over time [4]. While age plays a significant role in some cancers, such as thyroid, the notion that age is a significant prognostic factor in CRC has been controversial.

\footnotetext{
* Correspondence: yxyxlc@aliyun.com; tongjiandong@csco.org.cn

${ }^{2}$ Research Center of Cancer Prevention and Treatment, Medical College of Yangzhou University, Number 11, Huaihai Road, Yangzhou 225001, Jiangsu Province, People's Republic of China

'Department of Oncology, The Second Clinical School of Yangzhou University (Yangzhou NO.1 People's Hospital), Mid Hanjiang Road, Yangzhou 225009, Jiangsu Province, People's Republic of China
}

For example, various studies have reported poorer prognosis among young patients with CRC [5-7], while other authors have demonstrated that young patients with CRC surgically treated appeared to have a higher cancer specific survival (CSS) rate than elderly ones [8-10]. Some studies showed more advanced stages in old patients [11] whereas others did not [12]. Furthermore, the current definition of young or elderly patients with CRC remains controversial.

Although the majority of studies in the literature used the cutoff age of 40 to denote young patients with CRC [5,9,13-15], some other studies have used cutoff age of 30 [15,16], 25 [17] or others [18-20]. The definition of an elderly patient has included cutoffs ages of 60 [21], 70 [22], 75 [23] and even 80 years [24,25]. The majority of studies was individually limited by surgical resection, 
but did not consider the prognostic significance of age on patients who were not surgically treated.

Our primary objective in this study was to determine the impact of age on the primary outcomes of CSS and overall survival (OS) among patients with CRC treated or not treated with surgical resection using data from SEER (Surveillance, Epidemiology, and End Results) database. Our secondary objectives was to determine whether there were differences in clinicopathological characteristics at the time of diagnosis for the various age groups.

\section{Methods}

We used data from the SEER cancer registry to conduct this study. SEER, a population-based registry sponsored by the National Cancer Institute, collects information on cancer incidence and survival from 17 population-based cancer registries, including approximately $28 \%$ of the U.S. population [26]. SEER data contain no identifiers and are publicly available for studies on cancer-based epidemiology and health policy. The National Cancer Institute's SEER*Stat software (Surveillance Research Program, National Cancer Institute SEER"Stat software, www. seer.cancer.gov/seerstat) (Version 8.1.2) was used to identify patients whose pathological diagnosis was invasive CRC (C18.0-20.9) between 1996 and 2005. Only patients of adult age ( $\geq 15$ years) were included. Histology types were limited to adenocarcinoma $(8150 / 3,8210 / 3$, $8261 / 3$, 8263/3), mucinous adenocarcinoma (8480/3), and signet ring cell carcinoma (8490/3). Patients were excluded if they had in situ staging.

\section{Ethics statement}

This study was in compliance with the Helsinki Declaration. An independent ethics committee/institutional review board at Yangzhou University approved our study. Data released from the SEER database do not require informed patient consent because they contain no identifiers and were publicly available. We have got permission to access the research data file in the SEER program by National Cancer Institute, USA and the reference number was 11756-Nov2013.

\section{Statistical analysis}

Our use of the term "age" refers to "age at diagnosis" when not otherwise specified. Aside from ages 15-30 which were grouped together for a relatively small number of patients, other patients were stratified into 10year age groups. Rather than dichotomizing patients as younger versus older, use of ten-year age groups allowed for a more detailed analysis of treatment by age. The primary endpoint of this study was CRC-cause-specific survival (CCSS) which was calculated from the date of diagnosis to the date of cancer-specific death and was shown as "SEER cause-specific survival" in SEER database. Overall survival (OS) was calculated from the date of diagnosis to the date of death, which was indicated as "Vital Status" in the SEER database. Age, sex, race, TNM stage, tumor location, tumor grade, histological type, CCSS and, OS were assessed. Adjuvant chemotherapy was not evaluated, as the SEER registry does not include this information. TNM classification was restaged according to the criteria described in the American Joint Committee on Cancer (AJCC) Cancer Staging Manual (7th edition, 2010).

Chi-square $\left(\chi^{2}\right)$ tests were used for tests of independent parameters. Survival curves were generated using Kaplan-Meier estimates, and differences between curves were analyzed using the log-rank test. Multivariable Cox regression models were built for analysis of risk factors of survival outcomes. Exact 95\% confidence intervals (CIs) for proportions were calculated. The nonlinear effect of age on the hazard ratio (HR) of CRC-specific mortality was assessed using quintic polynomial regression, with the $\mathrm{R}^{2}$ reported. All statistical analysis was done using the statistical software package SPSS for Windows, version 17 (SPSS Inc., Chicago, IL, USA). Statistical significance was set at two-sided $\mathrm{P}<0.05$.

\section{Results}

\section{Clinicopathological differences between age groups}

We identified 226,430 eligible patients with CRC in the SEER database during the 10-year study period (between 1996 and 2005). In the 15-30 age group, there were 1,181 patients; 5,333 in the $31-40$ age group; 18,727 in the $41-50$ age group; 39,125 in the 51-60 age group; 53,540 in the $61-70$ age group; 64,642 in the $71-80$ age group and 43,882 in the $80+$ age group. The proportion of colon cancer patients and Caucasian patients gradually increased with age. Our 51-60, 61-70 and 7180 age groups had a significantly larger proportion of grade I/II tumors at presentation $(\mathrm{P}<0.001)$, as well as a significantly higher proportion of adenocarcinoma $(\mathrm{P}<0.001)$, The proportions of patients receiving surgical resection was roughly same for the 15-30 to 71-80 age group with proportions varying from $90.2 \%$ to $91.4 \%$, but it decreased to $84.1 \%$ for $80+$ age group. The proportions of patients with stage I/II CRC gradually increased from $27.6 \%$ in the $15-30$ age group to $46.0 \%$ in the $71-80$ age group, but it decreased to $44.9 \%$ in the $80+$ age group, which had highest proportion of unstaged patients $(\mathrm{P}<0.05)$ (Table 1).

\section{Impact of age on survival outcomes in patients with CRC}

We observed two significant findings. First, in the operated group, those aged 51-60 had the best prognosis with a 5 -year CCSS of $72.3 \%$ and a 5 -year OS of $68.3 \%$. 
Table 1 Characteristics of patients from SEER database by age

\begin{tabular}{|c|c|c|c|c|c|c|c|c|}
\hline Characteristic & $\begin{array}{l}15-30 \\
(n=1181)\end{array}$ & $\begin{array}{l}31-40 \\
(n=5333)\end{array}$ & $\begin{array}{l}41-50 \\
(n=18727)\end{array}$ & $\begin{array}{l}51-60 \\
(n=39125)\end{array}$ & $\begin{array}{l}61-70 \\
(n=53540)\end{array}$ & $\begin{array}{l}71-80 \\
(n=64642)\end{array}$ & $\begin{array}{l}>80 \\
(n=43882)\end{array}$ & $P$ value \\
\hline Site & & & & & & & & $<0.001$ \\
\hline Colon & 878 & 3854 & 13619 & 29335 & 42067 & 52767 & 36839 & \\
\hline$\%$ & $76.1 \%$ & $73.6 \%$ & $73.8 \%$ & $76.1 \%$ & $79.8 \%$ & $83.0 \%$ & $85.6 \%$ & \\
\hline Rectum & 276 & 1382 & 4823 & 9194 & 10625 & 10772 & 6205 & \\
\hline$\%$ & $23.9 \%$ & $26.4 \%$ & $26.2 \%$ & $23.9 \%$ & $20.2 \%$ & $17.0 \%$ & $14.4 \%$ & \\
\hline \multicolumn{9}{|l|}{ Sex } \\
\hline Male & 622 & 2881 & 10188 & 22876 & 30443 & 32157 & 16326 & $<0.001$ \\
\hline$\%$ & $52.7 \%$ & $54.0 \%$ & $54.4 \%$ & $58.5 \%$ & $56.9 \%$ & $49.7 \%$ & $37.2 \%$ & \\
\hline Female & 559 & 2452 & 8539 & 16249 & 23097 & 32485 & 27556 & \\
\hline$\%$ & $47.3 \%$ & $46.0 \%$ & $45.6 \%$ & $41.5 \%$ & $43.1 \%$ & $50.3 \%$ & $62.8 \%$ & \\
\hline Surgery Resection & & & & & & & & $<0.001$ \\
\hline Yes & 1073 & 4874 & 17025 & 35729 & 48909 & 58248 & 36890 & \\
\hline$\%$ & $90.9 \%$ & $91.4 \%$ & $90.9 \%$ & $91.3 \%$ & $91.4 \%$ & $90.2 \%$ & $84.1 \%$ & \\
\hline No & 98 & 416 & 1594 & 3150 & 4318 & 6017 & 6647 & \\
\hline$\%$ & $8.3 \%$ & $7.8 \%$ & $8.5 \%$ & $8.1 \%$ & $8.1 \%$ & $9.3 \%$ & $15.2 \%$ & \\
\hline Unknown & 10 & 43 & 105 & 243 & 292 & 347 & 316 & \\
\hline$\%$ & $0.8 \%$ & $0.8 \%$ & $0.6 \%$ & $0.6 \%$ & $0.5 \%$ & $0.5 \%$ & $0.7 \%$ & \\
\hline Grade & & & & & & & & $<0.001$ \\
\hline |/II & 687 & 3555 & 13196 & 28331 & 39003 & 46869 & 30960 & \\
\hline$\%$ & $58.2 \%$ & $66.7 \%$ & $70.5 \%$ & $72.4 \%$ & $72.8 \%$ & $72.5 \%$ & $70.6 \%$ & \\
\hline III/IV & 358 & 1232 & 3589 & 6649 & 9212 & 11727 & 8526 & \\
\hline$\%$ & $30.3 \%$ & $23.1 \%$ & $19.2 \%$ & $17.0 \%$ & $17.2 \%$ & $18.1 \%$ & $19.4 \%$ & \\
\hline Unknown & 136 & 546 & 1942 & 4145 & 5325 & 6046 & 4396 & \\
\hline$\%$ & $11.5 \%$ & $10.2 \%$ & $10.4 \%$ & $10.6 \%$ & $9.9 \%$ & $9.4 \%$ & $10.0 \%$ & \\
\hline Race & & & & & & & & $<0.001$ \\
\hline Caucasian & 865 & 3943 & 14062 & 30358 & 42785 & 54227 & 38195 & \\
\hline$\%$ & $73.2 \%$ & $73.9 \%$ & $75.1 \%$ & $77.6 \%$ & $79.9 \%$ & $83.9 \%$ & $87.0 \%$ & \\
\hline African American & 158 & 726 & 2689 & 5190 & 6144 & 5550 & 3101 & \\
\hline$\%$ & $13.4 \%$ & $13.6 \%$ & $14.4 \%$ & $13.3 \%$ & $11.5 \%$ & $8.6 \%$ & $7.1 \%$ & \\
\hline Others* & 153 & 637 & 1864 & 3361 & 4358 & 4604 & 2458 & \\
\hline$\%$ & $13.0 \%$ & $11.9 \%$ & $10.0 \%$ & $8.6 \%$ & $8.1 \%$ & $7.1 \%$ & $5.6 \%$ & \\
\hline Unknown & 5 & 27 & 112 & 216 & 253 & 261 & 128 & \\
\hline$\%$ & $0.4 \%$ & $0.5 \%$ & $0.6 \%$ & $0.6 \%$ & $0.5 \%$ & $0.4 \%$ & $0.3 \%$ & \\
\hline Histological Type & & & & & & & & $<0.001$ \\
\hline Adenocarcinoma & 833 & 4363 & 16225 & 34740 & 47536 & 56905 & 38431 & \\
\hline$\%$ & $72.2 \%$ & $82.5 \%$ & $86.9 \%$ & $89.0 \%$ & $88.9 \%$ & $88.1 \%$ & $87.7 \%$ & \\
\hline Mucinous/Signet-ring cancer & 320 & 927 & 2440 & 4308 & 5927 & 7655 & 5384 & \\
\hline$\%$ & $27.8 \%$ & $17.5 \%$ & $13.1 \%$ & $11.0 \%$ & $11.1 \%$ & $11.9 \%$ & $12.3 \%$ & \\
\hline AJCC stage & & & & & & & & $<0.001$ \\
\hline |- || & 326 & 1857 & 6736 & 15467 & 23031 & 29743 & 19712 & \\
\hline$\%$ & $27.6 \%$ & $34.8 \%$ & $36.0 \%$ & $39.5 \%$ & $43.0 \%$ & $46.0 \%$ & $44.9 \%$ & \\
\hline III -IV & 705 & 2828 & 9432 & 17834 & 22753 & 25328 & 15786 & \\
\hline
\end{tabular}


Table 1 Characteristics of patients from SEER database by age (Continued)

\begin{tabular}{llllllll}
\hline$\%$ & $59.7 \%$ & $53.0 \%$ & $50.4 \%$ & $45.6 \%$ & $42.5 \%$ & $39.2 \%$ & $36.0 \%$ \\
Unknown & 150 & 648 & 2559 & 5824 & 7756 & 9571 & 8384 \\
$\%$ & $12.7 \%$ & $12.2 \%$ & $13.7 \%$ & $14.9 \%$ & $14.5 \%$ & $14.8 \%$ & $19.1 \%$ \\
\hline
\end{tabular}

*Including American Indian/AK Native, Asian/Pacific Islander.

Patients in the 15-30 age group had reduced CCSS and OS rates, but they were better than those in the $80+$ age group, especially for OS. Second, in the non-operated group, there was continued worsening in CCSS and OS with increasing age, except for a slight increase in the 51-60 age group. The 5-year CCSS and OS rates decreased from $21.2 \%$ to $11.9 \%$ and from $18.2 \%$ to $4.3 \%$ in the 15-30 compared with $80+$ age group, respectively (Table 2).

The results of the univariate survival analysis and multivariable Cox proportional hazard regression analysis of age and various covariates with respect to CCSS in operated and non-operated groups are shown in Tables 3, 4, 5 and 6, and Figures 1 and 2. In the operated group, multivariable analysis demonstrated statistically significant increases in HR after age 60. Patients in the 61-70 age group were 1.1 times more likely to die of cancer than patients in the 51-60 age group. The risk was significantly higher for the patients in the 71-80 age group who were 1.3 times more likely to die of cancer than those in the 51-60 age group. Finally, the risk was higher still for patients in the $80+$ age group who were

Table 2 Long time survival rate (CSS/OS) in colorectal cancer by age

\begin{tabular}{|c|c|c|c|c|c|c|c|c|}
\hline & $15-30$ & $31-40$ & $41-50$ & $51-60$ & $61-70$ & $71-80$ & $>80$ & $P$ value \\
\hline Total & $(n=1181)$ & $(n=5333)$ & $(n=18727)$ & $(n=39125)$ & $(n=53540)$ & $(n=64642)$ & $(n=43882)$ & \\
\hline CSS & & & & & & & & $<0.001$ \\
\hline 1-year CCS & $84.6 \%$ & $88.8 \%$ & $88.8 \%$ & $88.7 \%$ & $86.8 \%$ & $82.8 \%$ & $74.2 \%$ & \\
\hline 3-year CCS & $66.4 \%$ & $72.7 \%$ & $73.3 \%$ & $75.1 \%$ & $74.1 \%$ & $70.4 \%$ & $60.0 \%$ & \\
\hline 5-year CCS & $58.5 \%$ & $65.7 \%$ & $66.3 \%$ & $68.0 \%$ & $67.6 \%$ & $64.0 \%$ & $53.5 \%$ & \\
\hline \multicolumn{9}{|l|}{ OS } \\
\hline 1-year OS & $83.5 \%$ & $87.9 \%$ & $87.8 \%$ & $87.2 \%$ & $83.9 \%$ & $77.3 \%$ & $63.8 \%$ & \\
\hline 3-year OS & $64.8 \%$ & $71.0 \%$ & $71.6 \%$ & $72.4 \%$ & $68.9 \%$ & $60.5 \%$ & $43.0 \%$ & \\
\hline 5-year OS & $56.6 \%$ & $63.6 \%$ & $63.5 \%$ & $64.0 \%$ & $60.0 \%$ & $49.9 \%$ & $30.5 \%$ & \\
\hline Operated group & $(n=1073)$ & $(n=4874)$ & $(n=17025)$ & $(n=35729)$ & $(n=48909)$ & $(n=58248)$ & $(n=36890)$ & \\
\hline 5-year CCS & & & & & & & & $<0.001$ \\
\hline 1-year CCS & $88.4 \%$ & $91.7 \%$ & $92.3 \%$ & $92.1 \%$ & $90.6 \%$ & $87.3 \%$ & $80.6 \%$ & \\
\hline 3-year CCS & $70.4 \%$ & $76.5 \%$ & $77.9 \%$ & $79.5 \%$ & $78.4 \%$ & $75.2 \%$ & $67.0 \%$ & \\
\hline 5-year CCS & $62.1 \%$ & $69.6 \%$ & $70.7 \%$ & $72.3 \%$ & $71.8 \%$ & $68.6 \%$ & $60.1 \%$ & \\
\hline \multicolumn{9}{|l|}{ OS } \\
\hline 1-year OS & $87.4 \%$ & $90.9 \%$ & $91.6 \%$ & $90.8 \%$ & $88.0 \%$ & $82.3 \%$ & $70.7 \%$ & \\
\hline 3-year OS & $69.1 \%$ & $75.1 \%$ & $76.3 \%$ & $76.8 \%$ & $73.4 \%$ & $65.5 \%$ & $49.5 \%$ & \\
\hline 5-year OS & $60.4 \%$ & $67.6 \%$ & $68.3 \%$ & $68.3 \%$ & $64.2 \%$ & $54.2 \%$ & $35.3 \%$ & \\
\hline Non-operated group & $(n=98)$ & $(n=416)$ & $(n=1594)$ & $(n=3150)$ & $(n=4318)$ & $(n=6017)$ & $(n=6647)$ & \\
\hline \multicolumn{9}{|l|}{ CSS } \\
\hline 1-year CCS & $42.7 \%$ & $55.6 \%$ & $50.2 \%$ & $50.3 \%$ & $43.0 \%$ & $37.4 \%$ & $36.5 \%$ & \\
\hline 3-year CCS & $25.2 \%$ & $27.2 \%$ & $23.4 \%$ & $25.6 \%$ & $23.3 \%$ & $20.7 \%$ & $17.0 \%$ & \\
\hline 5-year CCS & $21.2 \%$ & $20.3 \%$ & $18.4 \%$ & $19.7 \%$ & $18.3 \%$ & $16.7 \%$ & $11.9 \%$ & \\
\hline \multicolumn{9}{|l|}{ OS } \\
\hline 1-year OS & $41.1 \%$ & $54.0 \%$ & $48.1 \%$ & $47.6 \%$ & $38.7 \%$ & $30.7 \%$ & $26.3 \%$ & \\
\hline 3-year OS & $21.6 \%$ & $25.0 \%$ & $21.8 \%$ & $23.0 \%$ & $19.2 \%$ & $14.2 \%$ & $8.4 \%$ & \\
\hline 5-year OS & $18.2 \%$ & $18.0 \%$ & $16.4 \%$ & $17.0 \%$ & $14.0 \%$ & $9.8 \%$ & $4.3 \%$ & \\
\hline
\end{tabular}


Table 3 Univariate survival analyses of CRC patients in operated group according to various clinicopathological variables

\begin{tabular}{|c|c|c|c|c|}
\hline Variable & $\mathrm{n}$ & $\begin{array}{l}\text { 5-year } \\
\text { CCSS (\%) }\end{array}$ & $\begin{array}{l}\text { Log rank } \\
\chi^{2} \text { test }\end{array}$ & $\mathbf{P}$ \\
\hline Years of diagnosis & & & 65.374 & $<0.001$ \\
\hline 1996-2000 & 75517 & $67.5 \%$ & & \\
\hline 2001-2005 & 127231 & $69.5 \%$ & & \\
\hline Sex & & & 2.520 & 0.112 \\
\hline Male & 103083 & $69.0 \%$ & & \\
\hline Female & 99665 & $68.5 \%$ & & \\
\hline Site & & & 122.381 & $<0.001$ \\
\hline Colon & 127618 & $68.2 \%$ & & \\
\hline Rectum & 35530 & $71.6 \%$ & & \\
\hline Age & & & 1112.554 & $<0.001$ \\
\hline $15-30$ & 1073 & $62.1 \%$ & & \\
\hline $31-40$ & 4874 & $69.6 \%$ & & \\
\hline $41-50$ & 17025 & $70.7 \%$ & & \\
\hline $51-60$ & 35729 & $72.3 \%$ & & \\
\hline $61-70$ & 48909 & $71.8 \%$ & & \\
\hline $71-80$ & 58248 & $68.6 \%$ & & \\
\hline$>80$ & 36890 & $60.1 \%$ & & \\
\hline Race & & & 0.036 & 0.850 \\
\hline Caucasian & 166019 & $69.2 \%$ & & \\
\hline African American & 20149 & $61.6 \%$ & & \\
\hline Others* & 16580 & $72.4 \%$ & & \\
\hline Pathological grading & & & 812.382 & $<0.001$ \\
\hline |- || & 150521 & $72.0 \%$ & & \\
\hline III-IV & 38018 & $52.7 \%$ & & \\
\hline Unknown & 14209 & $77.2 \%$ & & \\
\hline Histological Type & & & 1162.165 & $<0.001$ \\
\hline Adenocarcinoma & 177748 & $70.0 \%$ & & \\
\hline Mucinous/Signet ring cancer & 25000 & $59.7 \%$ & & \\
\hline AJCC stage & & & 16776.287 & $<0.001$ \\
\hline । & 37364 & $92.6 \%$ & & \\
\hline$\|$ & 59213 & $81.5 \%$ & & \\
\hline III & 54234 & $61.3 \%$ & & \\
\hline IV & 27707 & $12.6 \%$ & & \\
\hline Unknown & 24230 & $81.8 \%$ & & \\
\hline No. of LNs dissected & & & 337.494 & $<0.001$ \\
\hline$<12$ & 116783 & $69.6 \%$ & & \\
\hline$\geq 12$ & 80248 & $69.0 \%$ & & \\
\hline Unknown & 5717 & $47.7 \%$ & & \\
\hline
\end{tabular}

*Including other (American Indian/AK Native, Asian/Pacific Islander) and unknowns.
Table 4 Univariate survival analyses of CRC patients in nonoperated group according to various clinicopathological variables

\begin{tabular}{lllll}
\hline Variable & $\mathbf{n}$ & $\begin{array}{l}\text { 5-year } \\
\text { CCSS (\%) }\end{array}$ & $\begin{array}{l}\text { Log rank } \\
\boldsymbol{X}^{2} \text { test }\end{array}$ & $\mathbf{P}$ \\
\hline Years of diagnosis & & & 8.182 & 0.004 \\
$1996-2000$ & 7617 & $16.6 \%$ & & \\
$2001-2005$ & 14623 & $16.5 \%$ & &
\end{tabular}

Sex

Male

Female

Site

Colon

Rectum

Age

15-30

$31-40$

$41-50$

$51-60$

$61-70$

$71-80$

$>80$

Race

Caucasian

African American

Others*

Pathological grading

- II

III-IV

Unknown

Histological Type

Adenocarcinoma

Mucinous/Signet ring cancer

AJCC stage

I

|| $189 \quad 64.7 \%$

III $\quad 128 \quad 46.0 \%$

IV $12202 \quad 3.5 \%$

Unknown

$9639 \quad 32.8 \%$

*Including other (American Indian/AK Native, Asian/Pacific Islander) and unknowns.

1.9 times more likely to die of cancer than 51-60 year old patients. Patients in the elderly age groups (61-70, $71-80$, and $80+$ ) had significantly worse survival than those in the $51-60$ age group $(\mathrm{P}<0.001)$, but the difference in survival between those in the 51-60 age group compared with the other three younger age groups (15$30,31-40,41-50)$ wasn't statistically significant $(\mathrm{P}>0.05)$ 
Table 5 Multivariate Cox model analyses of prognostic factors of CRC in operated group

\begin{tabular}{|c|c|c|c|}
\hline Variable & Hazard ratio & $95 \% \mathrm{Cl}$ & $\mathbf{P}$ \\
\hline Years of diagnosis & & & $<0.001$ \\
\hline 1996-2000 & 1.000 & Reference & \\
\hline 2001-2005 & 0.944 & $0.930-0.959$ & \\
\hline Site & & & $<0.001$ \\
\hline Colon & 1.000 & Reference & \\
\hline Rectum & 1.044 & $1.023-1.066$ & \\
\hline Age & & & $<0.001$ \\
\hline $15-30$ & 1.055 & $0.955-1.165$ & 0.294 \\
\hline $31-40$ & 0.954 & $0.906-1.005$ & 0.077 \\
\hline $41-50$ & 0.979 & $0.948-1.011$ & 0.203 \\
\hline $51-60$ & 1.000 & Reference & \\
\hline $61-70$ & 1.082 & $1.056-1.109$ & $<0.001$ \\
\hline $71-80$ & 1.325 & $1.294-1.356$ & $<0.001$ \\
\hline$>80$ & 1.951 & $1.902-2.002$ & $<0.001$ \\
\hline Pathological grading & & & $<0.001$ \\
\hline |- \| & 1.000 & Reference & \\
\hline III-IV & 1.443 & $1.418-1.468$ & $<0.001$ \\
\hline Unknown & 0.913 & $0.880-0.948$ & $<0.001$ \\
\hline Histological Type & & & $<0.001$ \\
\hline Adenocarcinoma & 1.000 & Reference & \\
\hline Mucinous/Signet ring cancer & 1.200 & $1.175-1.226$ & \\
\hline AJCC stage & & & $<0.001$ \\
\hline |- || & 1.000 & Reference & \\
\hline III- IV & 4.880 & $4.791-4.971$ & $<0.001$ \\
\hline Unknown & 1.170 & $1.130-1.210$ & $<0.001$ \\
\hline No. of LNs dissected & & & $<0.001$ \\
\hline$<12$ & 1.000 & Reference & \\
\hline$\geq 12$ & 0.793 & $0.780-0.806$ & $<0.001$ \\
\hline Unknown & 2.269 & $2.183-2.358$ & $<0.001$ \\
\hline
\end{tabular}

(Table 5). The plot of HRs in this subgroup showed a hook-shaped curve and HRs sharply increased in the above 60 age group (Table 5, Figure 3a).

In the non-operated groups, multivariable analysis demonstrated similar results with the operated group. The risk of death from CRC continued to increase in the above 60 age group, such that patients in the $61-70,71-80$ and $80+$ age groups were 1.2 , 1.5 and 1.9 times, respectively more likely to die of cancer than patients in the 51-60 age group. Those in the 15-30, 31-40, 41-50 age groups experienced similar CCSS compared with those in the 51-60 age group $(\mathrm{P}>0.05)$ (Table 6$)$. The curves of the HRs in these groups was steadily constant until the age of 40, when the HR started to apparently increase with increasing age (Table 6 and Figure 3b).
Table 6 Multivariate Cox model analyses of prognostic factors of CRC in non-operated group

\begin{tabular}{|c|c|c|c|}
\hline Variable & Hazard ratio & $95 \% \mathrm{Cl}$ & $\mathbf{P}$ \\
\hline Years of diagnosis & & & $<0.001$ \\
\hline $1996-2000$ & 1.000 & Reference & \\
\hline $2001-2005$ & 0.869 & $0.840-0.899$ & \\
\hline Sex & & & 0.881 \\
\hline Male & 1.000 & Reference & \\
\hline Female & 0.997 & $0.965-1.031$ & \\
\hline Site & & & $<0.001$ \\
\hline Colon & 1.000 & Reference & \\
\hline Rectum & 0.842 & $0.814-0.872$ & \\
\hline Age & & & $<0.001$ \\
\hline $15-30$ & 0.975 & $0.761-1.251$ & 0.845 \\
\hline $31-40$ & 0.886 & $0.784-1.002$ & 0.055 \\
\hline $41-50$ & 1.021 & $0.951-1.097$ & 0.567 \\
\hline $51-60$ & 1.000 & Reference & \\
\hline $61-70$ & 1.185 & $1.121-1.253$ & $<0.001$ \\
\hline $71-80$ & 1.463 & $1.388-1.543$ & $<0.001$ \\
\hline$>80$ & 1.859 & $1.762-1.961$ & $<0.001$ \\
\hline Race & & & $<0.001$ \\
\hline Caucasian & 1.000 & Reference & \\
\hline African American & 1.160 & $1.109-1.214$ & $<0.001$ \\
\hline Others* & 0.871 & $0.818-0.927$ & $<0.001$ \\
\hline Pathological grading & & & $<0.001$ \\
\hline |- || & 1.000 & Reference & \\
\hline III-IV & 1.430 & $1.365-1.498$ & $<0.001$ \\
\hline Unknown & 1.141 & $1.100-1.184$ & $<0.001$ \\
\hline Histological Type & & & 0.001 \\
\hline Adenocarcinoma & 1.000 & Reference & \\
\hline Mucinous/Signet ring cancer & 1.112 & $1.050-1.177$ & \\
\hline AJCC stage & & & $<0.001$ \\
\hline |- || & 1.000 & Reference & \\
\hline III- IV & 7.808 & $6.260-9.739$ & $<0.001$ \\
\hline Unknown & 2.735 & $2.192-3.412$ & $<0.001$ \\
\hline
\end{tabular}

*Including other (American Indian/AK Native, Asian/Pacific Islander) and unknowns.

\section{Discussion}

Conflicting results have been reported regarding whether age affects the prognosis of CRC. In general, it is assumed that young patients have a higher prevalence of mucinous or poorly differentiated tumors including signet ring carcinoma and later stage and elderly patients have a higher percentage of comorbidities and emergency surgeries, all of which means poorer prognosis compared with others. Whether age itself is an independent survival factor is unknown. Previous studies have demonstrated that 


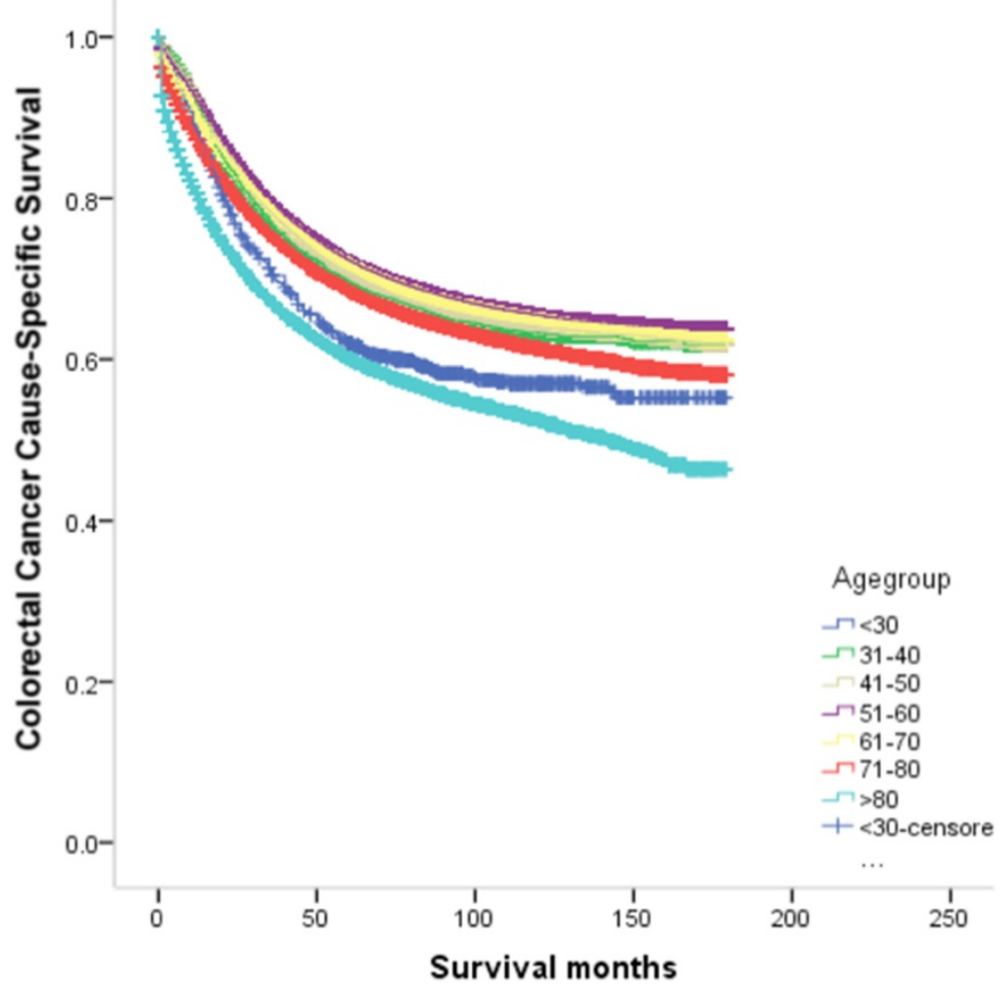

Figure 1 Survival curves according to each age subgroups in colorectal patients in operated group.

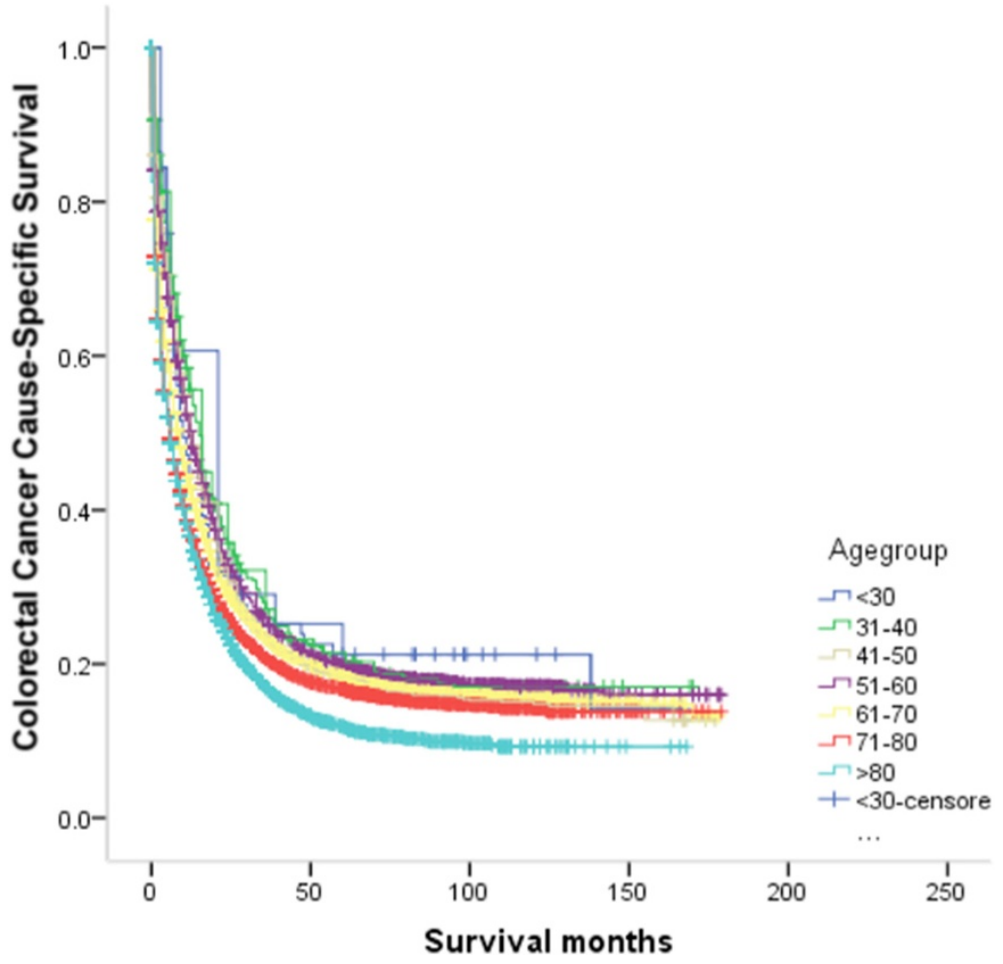

Figure 2 Survival curves according to each age subgroups in colorectal patients in non-operated group. 

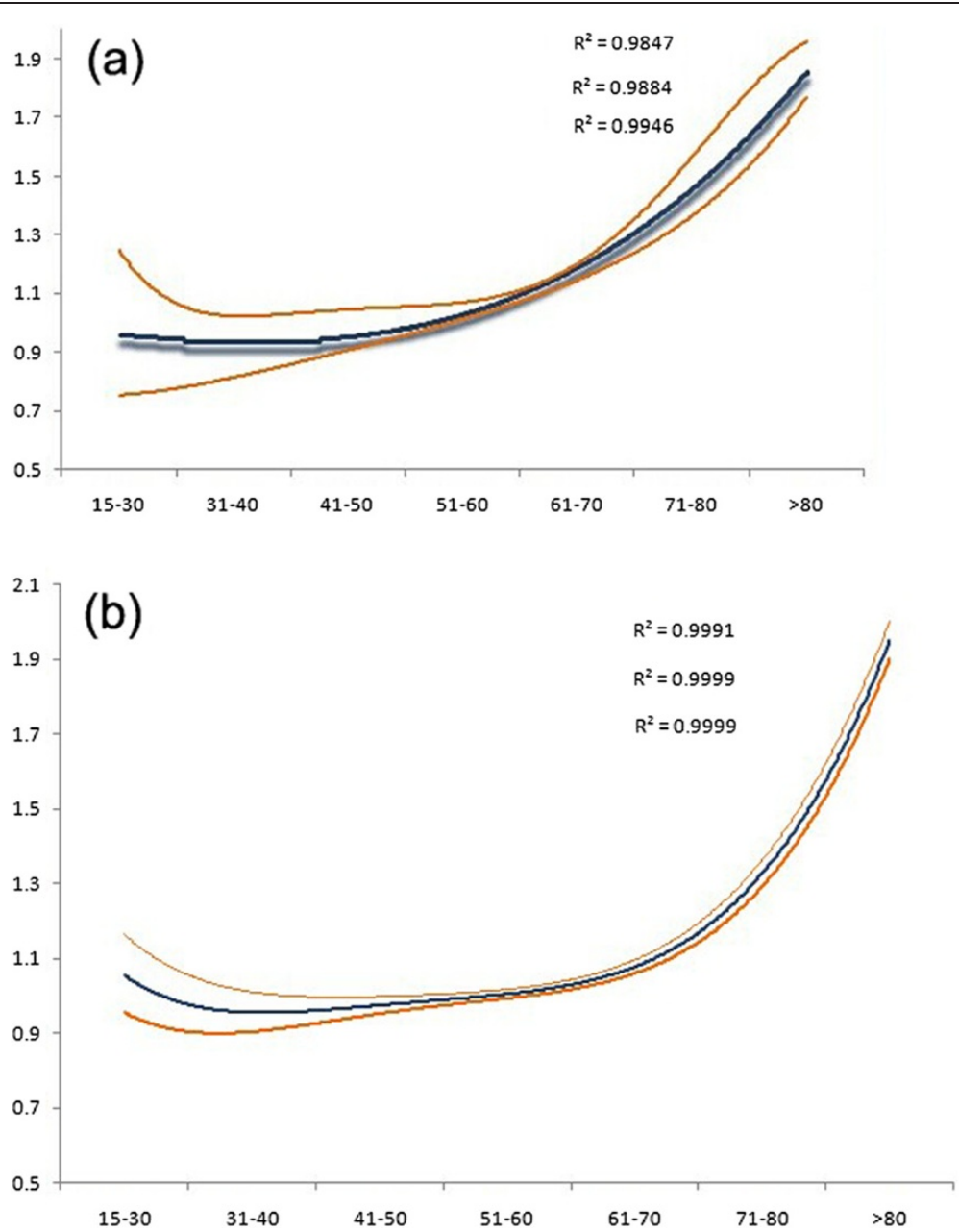

Figure 3 Estimates of hazard ratios (HRs) of colorectal cancer-specific mortality changing with age for (a) operated and (b) non-operated group using quintic polynomial regression. The solid blue lines represent the estimates of HRs, whereas the dotted orange lines represent the 95\% confidence intervals. All R2 values are reported.

age influences CSS in certain cancer types. One example is well differentiated thyroid cancer for which the American Joint Committee on Cancer (AJCC) incorporates age into its staging criteria: patients less than 45 years of age with well differentiated thyroid cancer cannot be diagnosed with stage III or IV disease [27].

In our study cohort, we found that patients in the 5160 age group had a relatively good prognosis, and the difference with elderly age groups (61-70-, 71-80, 80+) was statistically significant, but the difference between the 51-60 and younger groups was not significant. This result was validated in both operated and non-operated age groups. Although young patients always had a higher prevalence of later stage (stage III/IV) and mucinous, signet-ring and poorly differentiated tumors which tended to have a poorer prognosis compared with well and moderately differentiated tumors [28], the surgical resection rate and survival rate were comparable with other age groups in our study. What is interesting is that if patients didn't undergo surgical resection, the younger they were, the better was the prognosis.

Generally, CRC is thought to be a malignancy affecting mostly the elderly, with more than $90 \%$ of patients being diagnosed after age 55, and our study indicated that it seems reasonable to use 60 years as the cutoff between young and elderly patients. We then conducted an analysis comparing clinicopathological and survival analysis comparing groups of patients above and below 60 years of age, Young patients with CRC aged 60 and below had unfavorable clinicopathological characteristics, but they still had a higher CSS $(\chi 2=631.268, \mathrm{P}<0.001)$. (Additional file 1 : Table S1 and Additional file 2: Figure S1).

In general, young patients always had a good performance status, which is essential for the success of chemotherapy [29] and extensive lymphadenectomy. Clinicians are more inclined to use all therapeutic options, such as combination chemotherapy and surgery in young patients 
than elderly ones because they are in better health and are more likely to tolerate toxicities associated with chemotherapy $[10,30,31]$. In a retrospective large multi-institutional study, chemotherapy use in patients with stage III disease decreased with increasing age, with patients $>80$ years receiving adjuvant chemotherapy in only $25.6 \%$ of cases in comparison with $82.4 \%$ of cases in patients $<40$. For select patients with stage II disease, younger patients more frequently received chemotherapy than older patients $(69.2 \%$ for those $<40$ year, $46.0 \%$ for those $40-50,27.0 \%$ for those $50-80$ and $5.6 \%$ for those $>80$ years of age), and similar results were found in rectal cancer [32].

Increased adjuvant therapy use in younger patients may partially account for stage-specific increases in survival. Moreover, the sharp decline in the use of adjuvant therapy with increasing age could not be justified by the effect of comorbidities, treatment toxicity, short natural life expectancies, and health care $[32,33]$. In several institutional series, young patients more often received regional or surgical therapy compared with older patients $[13,34,35]$. Conversely, poor tolerance to treatment due to poor performance status or the presence of other comorbid medical conditions may contribute to inferior survival of older patients [12]. Chagpar et al. found that, among patients with stage III disease, older age was associated with under treatment, independent of preexisting comorbidities, as well as other clinical pathologic and socioeconomic factors [36].

When concerning metastatic CRC, several studies have shown a significant improvement in survival when comparing patients managed with primary tumor resection to those managed with chemotherapy alone [31,37-39], but in fact elderly patients are less likely to receive palliative surgery. Our data demonstrated that patients in the $80+$ age group had an extremely low surgical resection rate although they had relatively good clinicopathological characteristics. Less aggressive treatment offered to patients with limited comorbidities was likely to impact on their outcome [40].

Young patients also have a higher proportion of tumors demonstrating microsatellite instability, which are associated with a better prognosis [41]. Although survival of patients with advanced CRC has significantly increased in clinical trials incorporating new therapeutic agents [42], a meta-analysis comparing younger and older patients with advanced CRC enrolled in randomized clinical trials of newer chemotherapy agents between 1995 and 2004 demonstrated equal survival in both groups [43]. In fact, patients enrolled in clinical trials are always strictly selected and under thorough supervision. Our analysis of the SEER data demonstrated that the younger the patients were, the better their survival, even for patients who received no surgical therapy.
This study adds to current knowledge by answering more in-depth research questions about age and prognosis through analysis large population-based data from the SEER database, however, it had several potential limitations. First, the SEER database only had limited information on tumor factors, which could affect survival analysis. Second, concerning treatment modalities, the SEER definition of surgery does not separate treatment with palliative intent from that with curative intent. Thus, the beneficial effect of surgery on survival may be underestimated, specifically for those patients who underwent radical resection. Finally, the SEER database does not include information on comorbidities which limits our ability to calculate the impact of comorbid conditions on CSS. Various studies on CRC surgery and treatment outcomes show a progressive increase in postoperative morbidity and mortality with advancing age $[44,45]$, which are likely to impact their short-term survival. Moreover, some studies have shown that postoperative morbidity had a negative impact on long-term outcomes following radical surgery of various tumors [46-48]. Still, our study has sufficient power for a larger population-based study.

\section{Conclusions}

In conclusion, our study demonstrated that in the operated group, those aged 51-60 had the best prognosis, while in the non-operated groups, those of very young age 15-30 had the best prognosis. Both CCS and OS continued to decline with further advances in age after 60 as exemplified by worsening survival in the $>60$ age group. Recognition of these findings is important for clinicians who must consider if age should be incorporated into their assessments and treatment decisions for patients with CRC.

\section{Additional files}

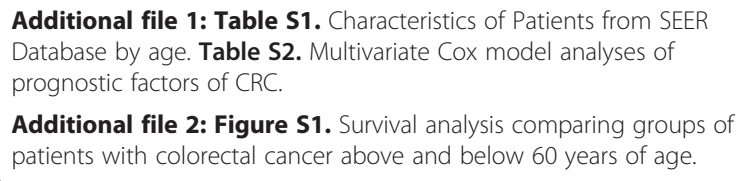

Additional file 1: Table S1. Characteristics of Patients from SEER Database by age. Table S2. Multivariate Cox model analyses of prognostic factors of CRC.

Additional file 2: Figure S1. Survival analysis comparing groups of patients with colorectal cancer above and below 60 years of age.

\section{Abbreviations}

CRC: Colorectal cancer; SEER: National Cancer Institute's Surveillance, Epidemiology, and End Results; AJCC: American Joint Committee on Cancer; CSS: Cause-specific survival rate; OS: Overall survival.

\section{Competing interests}

The authors declare that they have no competing interests.

\section{Authors' contributions}

$J \mathrm{~L}, J T$, LX designed the study, JL provided the databases, JL, ZW, XY assembled and analyzed the data. JL, ZW wrote manuscript. All authors read and approved the final manuscript.

Acknowledgments

The authors would like to thank SEER for open access to the database. 
Received: 4 August 2014 Accepted: 3 February 2015 Published online: 25 February 2015

\section{References}

1. Siegel R, Ma J, Zou Z, Jemal A. Cancer statistics, 2014. CA Cancer J Clin. 2014;64(1):9-29.

2. Ries LA, Wingo PA, Miller DS, Howe HL, Weir HK, Rosenberg HM, et al. The annual report to the nation on the status of cancer, 1973-1997, with a special section on colorectal cancer. Cancer. 2000;88(10):2398-424.

3. Atkin WS, Edwards R, Kralj-Hans I, Wooldrage K, Hart AR, Northover $J M$, et al. Once-only flexible sigmoidoscopy screening in prevention of colorectal cancer: a multicentre randomised controlled trial. Lancet. 2010;375(9726):1624-33.

4. O'Connell JB, Maggard MA, Liu JH, Etzioni DA, Livingston EH, Ko CY. Rates of colon and rectal cancers are increasing in young adults. Am Surg. 2003;69(10):866-72.

5. Taylor MC, Pounder D, Ali-Ridha NH, Bodurtha A, MacMullin EC. Prognostic factors in colorectal carcinoma of young adults. Can J Surg. 1988:31(3):150-3.

6. Cusack JC, Giacco GG, Cleary K, Davidson BS, Izzo F, Skibber J, et al. Survival factors in 186 patients younger than 40 years old with colorectal adenocarcinoma. J Am Coll Surg. 1996;183(2):105-12.

7. Marble K, Banerjee S, Greenwald L. Colorectal carcinoma in young patients. J Surg Oncol. 1992:51(3):179-82

8. Li Q, Cai G, Li D, Wang Y, Zhuo C, Cai S. Better Long-Term Survival in Young Patients with Non-Metastatic Colorectal Cancer after Surgery, an Analysis of 69,835 Patients in SEER Database. PLoS One. 2014;9(4):e93756.

9. Li M, Li JY, Zhao AL, Gu J. Do young patients with colorectal cancer have a poorer prognosis than old patients? J Surg Res. 2011;167(2):231-6.

10. Schellerer VS, Merkel S, Schumann SC, Schlabrakowski A, Fortsch T, Schildberg C, et al. Despite aggressive histopathology survival is not impaired in young patients with colorectal cancer: CRC in patients under 50 years of age. Int J Colorectal Dis. 2012;27(1):71-9.

11. Simmonds PD, Best L, George S, Baughan C, Buchanan R, Davis C, et al. Surgery for colorectal cancer in elderly patients: a systematic review. Colorectal Cancer. Lancet. 2000;356(9234):968-74.

12. Serra-Rexach JA, Jimenez AB, Garcia-Alhambra MA, Pla R, Vidan M, Rodriguez $P$, et al. Differences in the therapeutic approach to colorectal cancer in young and elderly patients. Oncologist. 2012;17(10):1277-85.

13. O'Connell JB, Maggard MA, Livingston EH, Yo CK. Colorectal cancer in the young. Am J Surg. 2004;187(3):343-8.

14. Karsten B, Kim J, King J, Kumar RR. Characteristics of colorectal cancer in young patients at an urban county hospital. Am Surg. 2008;74(10):973-6.

15. Neufeld D, Shpitz B, Bugaev N, Grankin M, Bernheim J, Klein E, et al. Young-age onset of colorectal cancer in Israel. Tech Coloproctol. 2009;13(3):201-4.

16. Kam MH, Eu KW, Barben CP, Seow-Choen F. Colorectal cancer in the young: a 12-year review of patients 30 years or less. Colorectal Dis. 2004;6(3):191-4

17. Kaplan MA, Isikdogan A, Gumus M, Arslan UY, Geredeli C, Ozdemir N, et al. Childhood, adolescents, and young adults $(</=25$ y) colorectal cancer: study of Anatolian Society of Medical Oncology. J Pediatr Hematol Oncol. 2013;35(2):83-9.

18. Ben-Ishay O, Brauner E, Peled Z, Othman A, Person B, Kluger Y. Diagnosis of colon cancer differs in younger versus older patients despite similar complaints. Isr Med Assoc J. 2013;15(6):284-7.

19. Mitry E, Benhamiche AM, Jouve JL, Clinard F, Finn-Faivre C, Faivre J. Colorectal adenocarcinoma in patients under 45 years of age: comparison with older patients in a well-defined French population. Dis Colon Rectum. 2001;44(3):380-7.

20. You YN, Xing Y, Feig BW, Chang GJ, Cormier JN. Young-onset colorectal cancer: is it time to pay attention? Arch Intern Med. 2012;172(3):287-9.

21. Ahmed S, Howel D, Debrah S. The influence of age on the outcome of treatment of elderly patients with colorectal cancer. J Geriatr Oncol. 2014;5 (2):133-40.

22. Chang GJ, Skibber JM, Feig BW, Rodriguez-Bigas M. Are we undertreating rectal cancer in the elderly? An epidemiologic study. Ann Surg. 2007;246 (2):215-21.

23. Bouassida M, Chtourou MF, Hamzaoui L, Sassi S, Mighri MM, Azzouz MM, et al. Clinico-Pathological Caracteristics, Therapeutic Features and Post- operative Course of Colorectal Cancer in Elderly Patients. J Clin Diagn Res. 2014;8(1):77-9.

24. Clark AJ, Stockton D, Elder A, Wilson RG, Dunlop MG. Assessment of outcomes after colorectal cancer resection in the elderly as a rationale for screening and early detection. Br J Surg. 2004;91(10):1345-51.

25. Al-Refaie WB, Parsons HM, Habermann EB, Kwaan M, Spencer MP, Henderson WG, et al. Operative outcomes beyond 30-day mortality: colorectal cancer surgery in oldest old. Ann Surg. 2011;253(5):947-52

26. Warren $J$, Klabunde CN, Schrag D, Bach PB, Riley GF. Overview of the SEERMedicare data: content, research applications, and generalizability to the United States elderly population. Med Care. 2002;40(8 Suppl):IV-3-18.

27. Edge S. American Joint Committee on Cancer. Lip and Oral Cavity, vol. 7. New York: Springer; 2010.

28. Adkins Jr RB, DeLozier JB, McKnight WG, Waterhouse G. Carcinoma of the colon in patients 35 years of age and younger. Am Surg. 1987;53(3):141-5.

29. Goodwin RA, Asmis TR. Overview of systemic therapy for colorectal cancer. Clin Colon Rectal Surg. 2009;22(4):251-6.

30. Chew MH, Koh PK, Ng KH, Eu KW. Improved survival in an Asian cohort of young colorectal cancer patients: an analysis of 523 patients from a single institution. Int J Colorectal Dis. 2009;24(9):1075-83.

31. Stillwell AP, Buettner PG, Ho YH. Meta-analysis of survival of patients with stage IV colorectal cancer managed with surgical resection versus chemotherapy alone. World J Surg. 2010;34(4):797-807.

32. Steele SR, Park GE, Johnson EK, Martin MJ, Stojadinovic A, Maykel JA, et al. The impact of age on colorectal cancer incidence, treatment, and outcomes in an equal-access health care system. Dis Colon Rectum. 2014;57(3):303-10.

33. Schrag D, Cramer LD, Bach PB, Begg CB. Age and adjuvant chemotherapy use after surgery for stage III colon cancer. J Natl Cancer Inst. 2001;93 (11):850-7.

34. You YN, Dozois EJ, Boardman LA, Aakre J, Huebner M, Larson DW. Youngonset rectal cancer: presentation, pattern of care and long-term oncologic outcomes compared to a matched older-onset cohort. Ann Surg Oncol. 2011;18(9):2469-76.

35. Lin JT, Wang WS, Yen CC, Liu JH, Yang MH, Chao TC, et al. Outcome of colorectal carcinoma in patients under 40 years of age. J Gastroenterol Hepatol. 2005;20(6):900-5.

36. Chagpar R, Xing Y, Chiang YJ, Feig BW, Chang GJ, You YN, et al. Adherence to stage-specific treatment guidelines for patients with colon cancer. J Clin Oncol. 2012;30(9):972-9.

37. Galizia $G$, Lieto $E$, Orditura $M$, Castellano $P$, Imperatore $V$, Pinto $M$, et al. First-line chemotherapy vs bowel tumor resection plus chemotherapy for patients with unresectable synchronous colorectal hepatic metastases. Arch Surg. 2008;143(4):352-8. discussion 358.

38. Ruo L, Gougoutas C, Paty PB, Guillem JG, Cohen AM, Wong WD. Elective bowel resection for incurable stage IV colorectal cancer: prognostic variables for asymptomatic patients. J Am Coll Surg. 2003;196(5):722-8

39. Bajwa A, Blunt N, Vyas S, Suliman I, Bridgewater J, Hochhauser D, et al. Primary tumour resection and survival in the palliative management of metastatic colorectal cancer. Eur J Surg Oncol. 2009;35(2):164-7.

40. Lemmens VE, Janssen-Heijnen ML, Verheij CD, Houterman S, Repelaer van Driel OJ, Coebergh JW. Co-morbidity leads to altered treatment and worse survival of elderly patients with colorectal cancer. Br J Surg. 2005;92(5):615-23.

41. Popat S, Hubner R, Houlston RS. Systematic review of microsatellite instability and colorectal cancer prognosis. J Clin Oncol. 2005;23(3):609-18.

42. Grothey A, Goldberg RM. A review of oxaliplatin and its clinical use in colorectal cancer. Expert Opin Pharmacother. 2004;5(10):2159-70.

43. Blanke CD, Bot BM, Thomas DM, Bleyer A, Kohne CH, Seymour MT, et al. Impact of young age on treatment efficacy and safety in advanced colorectal cancer: a pooled analysis of patients from nine first-line phase III chemotherapy trials. J Clin Oncol. 2011;29(20):2781-6.

44. Jafari MD, Jafari F, Halabi WJ, Nguyen VQ, Pigazzi A, Carmichael JC, et al. Colorectal Cancer Resections in the Aging US Population: A Trend Toward Decreasing Rates and Improved Outcomes. JAMA Surg. 2014;149(6):557-64

45. Latkauskas T, Rudinskaite G, Kurtinaitis J, Janciauskiene R, Tamelis A, Saladzinskas $Z$, et al. The impact of age on post-operative outcomes of colorectal cancer patients undergoing surgical treatment. BMC Cancer. 2005;5:153.

46. Matsuda A, Matsumoto S, Seya T, Matsutani T, Kishi T, Yokoi K, et al. Does postoperative complication have a negative impact on long-term outcomes following hepatic resection for colorectal liver metastasis?: a meta-analysis. Ann Surg Oncol. 2013;20(8):2485-92. 
47. Kulu Y, Tarantio I, Warschkow R, Kny S, Schneider M, Schmied BM, et al. Anastomotic Leakage Is Associated with Impaired Overall and Disease-Free Survival after Curative Rectal Cancer Resection: A Propensity Score Analysis. Ann Surg Oncol 2014

48. Li QG, Li P, Tang D, Chen J, Wang DR. Impact of postoperative complications on long-term survival after radical resection for gastric cancer. World J Gastroenterol. 2013;19(25):4060-5.

Submit your next manuscript to BioMed Central and take full advantage of:

- Convenient online submission

- Thorough peer review

- No space constraints or color figure charges

- Immediate publication on acceptance

- Inclusion in PubMed, CAS, Scopus and Google Scholar

- Research which is freely available for redistribution 